\title{
Lung function of infants with congenital lung lesions in the first year of life
}

Marjolein Spoel MD, PhD ${ }^{1}$, Kees P. van de Ven ${ }^{1}$ MD, Harm AWM Tiddens ${ }^{2}$ MD, PhD, Wim C.J. Hop PhD ${ }^{3}$, Rene MH Wijnen MD, PhD ${ }^{1}$, Dick Tibboel MD, PhD ${ }^{1}$, Hanneke IJsselstijn MD, PhD ${ }^{1}$; for the Congenital Lung Malformations Study Group

${ }^{1}$ Intensive Care and Department of Pediatric Surgery

2 Department of Pediatrics, division of Pediatric Respiratory Medicine

${ }^{3}$ Department of Biostatistics

Erasmus Medical Center / Sophia Children's Hospital, Rotterdam, The Netherlands

Corresponding author:

Marjolein Spoel, M.D.

Erasmus MC, Sophia Children's Hospital

Room Sk-1280, P.O. Box 2060, 3000 CB, Rotterdam, the Netherlands

Fax: +31-10-7036288

Phone: +31-10-7036067

E-mail: m.spoel@erasmusmc.nl

Key words:

Lung function testing

Congenital malformations

Infants

Lung morphology

Lung volume

Neonatal pulmonary

Running head: Infant lung function in congenital lung lesions 


\section{Abstract}

\section{Background:}

Several studies have evaluated short-term neonatal outcome in infants with congenital lung lesions (CLL) but clinical course and lung function on the longer term have not yet been documented. We hypothesized that clinical course and lung function would be affected negatively by surgical resection.

Objective:

To evaluate respiratory symptoms and lung function longitudinally in the first year of life in infants with CLL and analyse differences herein between infants managed by observation only and infants whose affected lung parts were resected.

\section{Methods}

In 30 patients with CLL we evaluated respiratory symptoms and lung function at 6 and 12 months. Functional residual capacity $\left(\mathrm{FRC}_{\mathrm{p}}\right)$ and maximal expiratory flow at functional residual capacity (V'max $\mathrm{FRC}$ ) were measured with body plethysmography. SD-scores were calculated for V'max FRC. .

\section{Results}

Prevalence of respiratory symptoms did not differ between the groups. Mean $\mathrm{FRC}_{\mathrm{p}}(95 \% \mathrm{Cl}$ ) was 25.3 (23.3-27.3) in the group managed by observation vs. $27.3(25.1-29.6)$ in the group managed by surgery $(p=0.149)$. Mean $(95 \% \mathrm{Cl})$ SDS $V^{\prime} \max _{\text {FRC }}$ was $-1.45(-1.84$ to -1.06$)$ vs. $-1.41(-1.90$ to -0.91$)(p=0.892)$. Lung function did not change significantly over the six month period.

\section{Conclusion}

Surgical resection did not seem to have negatively affected clinical course and lung function. We recommend pulmonary follow-up of all CLL patients into adulthood to further identify any long term effects of CLL and observation or surgery. 


\section{Introduction}

Congenital malformations of the lung are rare with a reported estimate prevalence of one in 11.000-35.000 pregnancies and vary widely in their presentation and severity [1-3]. Advances in antenatal diagnostic techniques have improved the detection and characterisation of congenital lung lesions (CLL) [4]. The differential diagnosis of lung lesion includes congenital cystic adenomatoid malformation (CCAM), bronchopulmonary sequestration (BPS), bronchogenic cyst (BC) and congenital lobar emphysema (CLE). CCAMs are characterised by hamartomous growth of terminal respiratory structures deriving their blood supply from the pulmonary vasculature. BPSs are masses of non-functioning lung tissue, either in intralobar or extralobar form. BCs result from abnormal budding of the foregut, are usually unilocular, mostly located in the mediastinum and do not communicate with the airway [5]. CLE is a term used to describe a distended hyperlucent lobe, usually the left upper or right middle lobe, perhaps resulting from transient bronchial obstruction in utero [6].

Natural courses of CLL in utero from severe hydrops to total regression have been observed [7]. In the perinatal period, air trapping within the cystic component of CCAM can result in life-threatening respiratory distress requiring immediate surgical intervention. Later in life, communication of the cysts with the airways can result in recurrent pneumonia for which surgical resection of the affected lung part(s) is indicated. Controversy remains whether asymptomatic lesions should be resected. Some centers prefer elective resection at 3-6 months to reduce the risk of infection [1]; others prefer observation only because asymptomatic lesions may regress spontaneously [8-9].

Several studies evaluated short-term neonatal outcome but to our knowledge, lung function in the first year of life has not yet been documented. We hypothesized that clinical course and lung function parameters would be negatively affected by surgical resection. We report a prospective study in infants with CLL in which we established the respiratory morbidity at 6 and 12 months of life and analysed differences between infants with asymptomatic lesions, managed by observation, and those whose affected lung part(s) were resected. We also studied possible associations between clinical characteristics and lung function parameters.

\section{Methods}

Detailed information on methods is available online. We recorded demographic and clinical data of all CLL patients born in our centre between May 2005 and September 2010. We distinguished 2 groups: an observation group of asymptomatic infants and a surgical group whose affected lung (parts) were resected because of respiratory distress. The study was part of a routine follow-up program for CLL patients in which lung function, growth and developmental parameters are regularly assessed until 18 years [10-11]. The Medical Ethical Review Board Erasmus MC stated that "the Medical Research in Human Subjects Act does not apply to this research proposal, since subjects are not being submitted to any handling, nor are there rules of human behaviour being imposed". Therefore approval was waived. All parents were informed and provided permission to use the data for research purposes.

\section{Respiratory morbidity and physical growth}

The infants were physically examined at the ages of 6 and 12 months. Examination included anthropometry and pulmonary auscultation. Respiratory rate (RR) was measured during lung function assessment. Clinical data on respiratory morbidity were recorded at both visits. 


\section{Infant lung function tests}

Infant lung function tests were done as described previously at the ages of 6 and 12 months (corrected for prematurity), if children were clinically stable [12]. Plethysmographic functional residual capacity $\left(F R C_{p} ; \mathrm{mL} / \mathrm{kg}\right)$ was the primary outcome measure. Secondary outcome measures were the following: the standard deviation score (SDS) of forced expiratory flow at $\mathrm{FRC}_{\mathrm{p}}\left(\mathrm{V}^{\prime} \mathrm{max}_{\mathrm{FRC}}\right)$, respiratory symptoms, and anthropometric SDS.

\section{Data analysis}

Group comparisons were made with Mann Whitney U tests. Repeated measurements ANOVA served to evaluate lung function and growth parameters. The influence of clinical parameters on lung function was investigated with Univariate Mixed Models. For lung function and growth parameters, SDS <-1.96 (2.5th percentile of reference population) was considered abnormally low. The significance level was set at $\mathrm{p}<0.05$.

\section{Results}

Between May 2005 and December 2010, 55 of 57 newborns with a CLL survived (96\%). For logistic reasons the survivors were gradually included in the follow-up program. Seventeen $(31 \%)$ patients included after the first year of life were excluded from this study. Two other, asymptomatic, patients had serious neurological co-morbidity (1 with a chromosomal anomaly, 1 with Filamin A deficiency) as contraindication for lung function testing. Parents of 5 patients refused follow-up. One patient was awake during the first measurement and suffered from a RTI at the second occasion. Eventually, 30 of the 55 eligible patients (55\%) participated in the follow-up program.

Participants' birth weight was significantly lower than that of the non-participants (median 2930 (1650-4200) g versus median 3580 (2450-4505) g; $p=0.013$ ). Other perinatal characteristics did not significantly differ between participants and non-participants (data not shown). Fifteen participants were measured at both time-points, 5 at 6 months only and 10 at 12 months only (Figure online). Reasons for not completing both measurements were delayed inclusion ( $n=7), \operatorname{RTI}(n=3)$, being awake $(n=2)$, and logistic reasons $(n=3)$. Clinical characteristics of participants are shown in Table 1. In 23/30 patients $(77 \%)$ the lung lesion had been identified by antenatal ultrasound scan. Thirteen (43\%) developed respiratory symptoms and underwent resection at a median age of 3 weeks (range 0-39 weeks): lobectomy $n=8$; pneumonectomy $\mathrm{n}=2$ (one needed treatment with veno-arterial extracorporeal membrane oxygenation); non-anatomical resection $\mathrm{n}=3$. All patients were ventilated post-operatively; two were extubated on the day of surgery. Seven patients in the surgical group had been diagnosed antenatally: CCAM in 6 and congenital diaphragmatic hernia in 1. Postoperatively, the diagnosis CCAM was confirmed in 5 cases. One patient appeared to have a bronchopulmonary sequester. The other six patients in the surgical group were diagnosed postnatally. In five cases this diagnosis was confirmed by histology (1 CLE, 1 BC, 2 BPS and 1 CCAM). In one patient an eventration of the diaphragm was suspected which during surgery and on histology appeared to be a broncho-pulmonary sequestration. Until now, all asymptomatic patients remained without symptoms. One underwent embolisation of the supplying artery of an extralobar bronchopulmonary sequestration at the age of 3.4 years due to cardiac insufficiency. No malignancies have been observed histologically

\section{Respiratory morbidity and physical growth}

All 13 patients in the surgical group suffered from respiratory distress. Prevalences of respiratory symptoms did not significantly differ between the observation and surgical groups at 6 and 12 months (Table 2). Overall, significantly more therapeutic courses of antibiotics had been prescribed between 0-6 months than between 6-12 months $(p=0.018)$. This difference did not reach statistical significance in the subgroups separately. Number of courses of antibiotics for RTI or respiratory symptoms did not differ between these two periods (Table 2). 
There were no significant differences in SDS weight and SDS height between both groups. Overall, SDS weight at 12 months was significantly below normal $(p=0.037$, Table 2$)$.

\section{Infant lung function tests}

The median postnatal age at the two respective time points was 30 weeks (range 23-40 weeks, $n=20$ ) and 54 weeks (range 49-72 weeks, $\mathrm{n}=25$ ). Reliable $\mathrm{FRC}_{\mathrm{p}}$ measurements were obtained in 20 and 24 patients at 6 and 12 months respectively. Reliable V'max $\operatorname{FRC}_{\mathrm{FC}}$ measurements were obtained in 19 and 25 patients at 6 and 12 months respectively. Results are shown in Table 1, Figures 1 and 2. $\mathrm{FRC}_{\mathrm{p}}$ and SDS V'max $\mathrm{FRC}_{\mathrm{FC}}$ did not significantly differ between the observation and surgical group ( $p=0.796$ and $p=0.553$ respectively). Mean $(95 \% \mathrm{Cl}) \mathrm{FRC}_{\mathrm{p}}$ was $25.3(23.3-27.3)$ in the observation group vs. $27.3(25.1-29.6)$ in the surgical group $\left(\mathrm{p}=0.149\right.$; mean $(95 \% \mathrm{Cl})$ SDS V' $\max _{\mathrm{FRC}}$ was $-1.45(-1.84$ to $1.06)$ vs. $-1.41(-1.90$ to -0.91$)(\mathrm{p}=0.892)$ and did not change significantly over time. All $F R C_{p}$ values were $>13 \mathrm{~mL} / \mathrm{kg}$. Fifty percent of $\mathrm{FRC}_{\mathrm{p}}$ measurements were $>26 \mathrm{~mL} / \mathrm{kg}$; i.e. in $13 / 26(50 \%)$ patients in the observational group and 9/18 $(50 \%)$ patients in the surgical group. Mean SDS V'max ${ }_{F R C}$ was below normal at both time points in both groups. In the observational group $8 / 26$ patients $(31 \%)$ and $7 / 18(39 \%)$ surgical patients had a SDS V'max FRC $<-1.96$.

\section{Associations between lung function parameters and clinical characteristics}

We found no significant associations between $\mathrm{FRC}_{\mathrm{p}}$ and SDS V'max ${ }_{\mathrm{FRC}}$ and gestational age, birth weight, log duration of ventilation, log duration of supplemental oxygen and observation or surgery at both time points.

\section{Discussion}

To our knowledge this is the first longitudinal study that evaluated lung function and respiratory morbidity in the first year of life in infants with a CLL. In contrast to our hypothesis, both $\mathrm{FRC}_{\mathrm{p}}$ and $\mathrm{V}^{\prime} \mathrm{max}_{\mathrm{FRC}}$ did not differ between the two subgroups. $\mathrm{FRC}_{\mathrm{p}}$ values were in the upper or above normal range without a significant change from 6 to 12 months. SDS $V^{\prime}$ max $_{\mathrm{FRC}}$ was significantly below normal at 6 and 12 months without a significant change from 6 to 12 months. We found no significant associations between clinical characteristics and lung function parameters.

Several studies on CLL describe antenatal observations and perinatal outcome. Malignant transformation was described but this issue remains controversial [3]. In our surgical group, no malignancies were observed. The management of initially asymptomatic lesions deserves attention because complications may arise like pneumonia, pneumothorax, hemoptysis and hemothorax [3]. Some centres recommend early surgical intervention to prevent these complications; this would also stimulate compensatory lung growth [1,13-14]. Marshall and colleagues reported that elective resection in asymptomatic patients was associated with shorter hospital stay and a trend towards lower major complication rates and overall decreased medical costs. The sample size however was too small to have statistical power [15]. Observational management may be warranted because asymptomatic lesions may remain asymptomatic or regress spontaneously. In the present study we looked at outcome parameters beyond the perinatal period to justify a policy of observation in asymptomatic patients.

Compensatory lung growth after extensive resection of lung tissue was described in several (animal) studies [16-18]. However, our results do not testify to compensatory lung growth during children's first year of life. $\mathrm{FRC}_{\mathrm{p}}$ measurements were in the upper normal or above normal range in both groups and did not change significantly from 6 to 12 months. $F R C_{p}$ is considered to represent lung volume during quiet breathing. However, as we observed previously, $\mathrm{FRC}_{\mathrm{p}}$ seems a poor estimate of the volume of functional lung parenchyma in infants with CLL [12]. Enlarged, air filled spaces in the lung parenchyma cause hyperinflation, reflected by increased $F R C_{p}$. Also, $F R C_{p}$ values did not significantly differ between the 
observation and surgical groups. We speculate this is due to hyperinflation of the remaining lung tissue or to the presence of residual abnormal lung tissue.

Airway patency as measured by V'max ${ }_{\mathrm{FRC}}$ was significantly below normal at both 6 and 12 months, and to the same extent in both subgroups. We assume, therefore, that this may be a consequence of the anatomical anomaly itself and not of surgical treatment and/or the subsequent mechanical ventilation. The hyperinflated cystic, or in some cases more solid, lesions can compress the surrounding structures which can result in a mediastinal shift observable on a chest $\mathrm{X}$-ray or CT scan [14]. In 2009, Keijzer et al. performed pulmonary function tests in 14 CLL children (mean age 10 years) who all had undergone lobectomy. Test results pointed at mild airflow obstruction in all, irrespective of surgery having been performed before or after the $2^{\text {nd }}$ year of life [19].

In our study, respiratory morbidity was not significantly different between both subgroups. Only few patients needed inhalation medication ( $11 \%$ and $3 \%$ at 6 and 12 months respectively) or hospital admission for RTI (7\% and $3 \%$ at 6 and 12 months respectively). In contrast with our initial hypothesis, clinical course was not influenced negatively by surgery. We conclude that resection of congenital cystic lung lesions in the first weeks of life is tolerated well.

A limitation of our study is the heterogeneity in the types of CLL and the consequently small numbers per type. Four different types of CLL were included with CCAM and BPS as the largest groups. However, type of CLL seemed to be of lesser importance as this was not our primary research question. Repeated measurements could be obtained in only $15 / 30$ patients (50\%). However, repeated measurements ANOVA may have reduced the chance of a type II error. Multicenter studies allowing for larger samples are recommendable. Another potential limitation is the lack of a healthy control group. Sedation of healthy infants for research purposes is not permitted in the Netherlands; therefore we had to use lung function reference values published by others. We expressed $\mathrm{FRC}_{\mathrm{p}}$ values in $\mathrm{mL} / \mathrm{kg}$ as described previously. The normal range of $\mathrm{FRC}_{\mathrm{p}}$ is $13-26 \mathrm{~mL} / \mathrm{kg}$, mean 19.6, SD 3.4 [20]. Regarding V'max $\mathrm{FRC}$, we used references values based on a large representative population of healthy infants that others have used testing with similar equipment as we did [21]. Another potential limitation is the lack of measurements shortly after birth or preoperatively. Five symptomatic patients needed respiratory support for respiratory distress shortly after birth. Our institution is not equipped for infant lung function testing in these circumstances. We recommend to use gas mixing techniques - which can be applied shortly after birth - to evaluate homogeneity of ventilation longitudinally in unsedated infants not on ventilatory support [22].

In conclusion, we found no significant differences in respiratory morbidity and infant lung function parameters between the observation and surgical groups. However, we assume that $\mathrm{FRC}_{\mathrm{p}}$ is not suitable to assess possible compensatory lung growth in the first year of life after resection of lung part(s). The natural course of antenatally detected lung lesions could well be documented by standardized serial prenatal evaluation of the dimensions of lesion(s), routine assessment of the mediastinal shift together with postnatal imaging of the pulmonary vasculature at set moments in the first months of life. We recommend prolonged pulmonary follow-up of lung structure and function.

\section{Acknowledgements:}

The authors thank the staff of the Erasmus MC lung function lab, and especially Eveline Nieuwhof, for their hospitality and cooperation. We also thank the following members from the Congenital Lung Malformations Group, and especially Titia E Cohen-Overbeek from the Department of Gyneacology and Obstetrics and Lex PWM Maat from the Department 
of Cardio-Thoracic Surgery for their careful assessment and advices on the manuscript. The manuscript is written on behalf of the Congenital Lung Malformations Study Group which consists of (excluding the authors): John Vlot (pediatric surgeon), Saskia J Gischler (pediatrician), Johan C de Jongste, Mariëlle WH Pijnenburg, Hetty M Janssens (pediatric pulmonologists), $\mathrm{P}$ van de Woestijne (cardiothoracic surgeons).

The Swart-van Essen foundation financially supported this study. Ko Hagoort provided editorial advice. 


\section{References}

1 Chen HW, Hsu WM, Lu FL, Chen PC, Jeng SF, Peng SS, Chen CY, Chou HC, Tsao PN, Hsieh WS: Management of congenital cystic adenomatoid malformation and bronchopulmonary sequestration in newborns. Pediatr Neonatol 2010;51:172-177.

2 Kumar B, Agrawal LD, Sharma SB: Congenital bronchopulmonary malformations: A single-center experience and a review of literature. Ann Thorac Med 2008;3:135-139.

3 Laberge JM, Puligandla P, Flageole H: Asymptomatic congenital lung malformations. Semin Pediatr Surg 2005;14:16-33.

4 Witlox RS, Lopriore E, Oepkes D, Walther FJ: Neonatal outcome after prenatal interventions for congenital lung lesions. Early Hum Dev 2011;87:611-618.

5 Tran H, Fink MA, Crameri J, Cullinane F: Congenital cystic adenomatoid malformation: Monitoring the antenatal and short-term neonatal outcome. Aust N Z J Obstet Gynaecol 2008;48:462-466.

6 Olutoye OO, Coleman BG, Hubbard AM, Adzick NS: Prenatal diagnosis and management of congenital lobar emphysema. J Pediatr Surg 2000;35:792-795.

7 Hadchouel A, Benachi A, Revillon Y, Rousseau V, Martinovic J, Verkarre V, Dumez Y, Delacourt C: Factors associated with partial and complete regression of fetal lung lesions. Ultrasound Obstet Gynecol 2011;38:88-93.

8 Aziz D, Langer JC, Tuuha SE, Ryan G, Ein SH, Kim PC: Perinatally diagnosed asymptomatic congenital cystic adenomatoid malformation: To resect or not? J Pediatr Surg 2004;39:329-334; discussion 329-334.

9 Langston C: New concepts in the pathology of congenital lung malformations. Semin Pediatr Surg 2003;12:1737.

10 Gischler SJ, van der Cammen-van Zijp MH, Mazer P, Madern GC, Bax NM, de Jongste JC, van Dijk M, Tibboel $\mathrm{D}$, ljsselstijn $\mathrm{H}$ : A prospective comparative evaluation of persistent respiratory morbidity in esophageal atresia and congenital diaphragmatic hernia survivors. J Pediatr Surg 2009;44:1683-1690.

11 Gischler SJ, Mazer P, Duivenvoorden HJ, van Dijk M, Bax NM, Hazebroek FW, Tibboel D: Interdisciplinary structural follow-up of surgical newborns: A prospective evaluation. J Pediatr Surg 2009;44:1382-1389.

12 Spoel M, van den Hout L, Gischler SJ, Hop WC, Reiss I, Tibboel D, de Jongste JC, Ijsselstijn H: Prospective longitudinal evaluation of lung function during the first year of life after repair of congenital diaphragmatic hernia. Pediatr Crit Care Med 2011

13 Adzick NS: Management of fetal lung lesions. Clin Perinatol 2003;30:481-492.

14 Laje P, Liechty KW: Postnatal management and outcome of prenatally diagnosed lung lesions. Prenat Diagn 2008;28:612-618.

15 Marshall KW, Blane CE, Teitelbaum DH, van Leeuwen K: Congenital cystic adenomatoid malformation: Impact of prenatal diagnosis and changing strategies in the treatment of the asymptomatic patient. AJR Am $\mathrm{J}$ Roentgenol 2000;175:1551-1554.

16 Hsia CC, Herazo LF, Fryder-Doffey F, Weibel ER: Compensatory lung growth occurs in adult dogs after right pneumonectomy. J Clin Invest 1994;94:405-412.

17 Takeda S, Hsia CC, Wagner E, Ramanathan M, Estrera AS, Weibel ER: Compensatory alveolar growth normalizes gas-exchange function in immature dogs after pneumonectomy. J Appl Physiol 1999;86:1301-1310.

18 Yilmaz C, Ravikumar P, Dane DM, Bellotto DJ, Johnson RL, Jr., Hsia CC: Noninvasive quantification of heterogeneous lung growth following extensive lung resection by high-resolution computed tomography. J Appl Physiol 2009;107:1569-1578.

19 Keijzer R, Chiu PP, Ratjen F, Langer JC: Pulmonary function after early vs late lobectomy during childhood: A preliminary study. J Pediatr Surg 2009;44:893-895. 
Hulskamp G, Hoo AF, Ljungberg H, Lum S, Pillow JJ, Stocks J: Progressive decline in plethysmographic lung volumes in infants: Physiology or technology? Am J Respir Crit Care Med 2003;168:1003-1009.

21 Hoo AF, Dezateux C, Hanrahan JP, Cole TJ, Tepper RS, Stocks J: Sex-specific prediction equations for vmax(frc) in infancy: A multicenter collaborative study. Am J Respir Crit Care Med 2002;165:1084-1092.

22 Frey U: Clinical applications of infant lung function testing: Does it contribute to clinical decision making? Paediatr Respir Rev 2001;2:126-130. 


\begin{tabular}{|c|c|c|c|c|}
\hline Variables & Total & $\begin{array}{l}\text { Observation } \\
\text { group }\end{array}$ & $\begin{array}{l}\text { Surgical } \\
\text { group }\end{array}$ & $\begin{array}{l}\text { between } \\
\text { groups } p\end{array}$ \\
\hline $\mathrm{N}$ & 30 & 17 & 13 & \\
\hline Males & $21(70)$ & $13(76)$ & $8(62)$ & 0.385 \\
\hline Gestational age (wks) & \multicolumn{3}{|c|}{$39.1(38.0-41.0) 39.6(37.1-41.6) 40.0$ (34.7-41.7) 0.950} & \\
\hline Birth weight (grams) & $3490(3000-4505)$ & $3585(2450-4200)$ & $3730(2925-4505)$ & 0.601 \\
\hline Type lung lesion & & & & 0.887 \\
\hline CCAM & $17(57)$ & $10(59)$ & $7(54)$ & \\
\hline BPS & $9(30)$ & $5(29)$ & $4(31)$ & \\
\hline CLE & $3(10)$ & $2(12)$ & $1(8)$ & \\
\hline $\mathrm{BC}$ & $1(3)$ & 0 & $1(8)$ & \\
\hline Duration ventilation (days) & $0(0-40)$ & $0(0-10)$ & $2(0-40)$ & $<0.001$ \\
\hline Conventional & $0(0-38)$ & $0(0-10)$ & $2(0-38)$ & $<0.001$ \\
\hline $\mathrm{HFO}$ & $0(0-11)$ & 0 & $0(0-11)$ & 0.016 \\
\hline Duration oxygen supply (days) & $4(0-42)$ & $0(0-10)$ & $5(0-42)$ & $<0.001$ \\
\hline
\end{tabular}

Table 1: CCAM: congenital cystic adenomatoid malformation, BPS: bronchopulmonary sequestration, BC: bronchogenic cyst, CLE: congenital lobar emphysema. HFO: high frequency oscillatory ventilation. $\mathrm{P}$ values are given for the differences between patients in the observation and surgical groups. Data demonstrated as number (\%), median (range) or mean (SD) where appropriate. One asymptomatic CCAM patient had a laryngeal cyst causing upper airway compression, after resection of this specific lesion 10 days of mechanical ventilation were necessary.

* significantly below normal (SDS=0), one sample t-test was used. 
Table 2: Respiratory symptoms, growth and lung function at 6 and 12 months

\begin{tabular}{|c|c|c|c|c|}
\hline \multirow{2}{*}{$\begin{array}{l}\text { Age } \\
\text { Resection }\end{array}$} & \multicolumn{2}{|l|}{$6 \mathrm{mos}$} & \multicolumn{2}{|l|}{12 mos } \\
\hline & No & Yes & No & Yes \\
\hline \multicolumn{5}{|l|}{$\mathrm{RTI}$ with $\mathrm{AB}$ treatment } \\
\hline None $\quad(n, \%)$ & $9 / 17(53)$ & $6 / 13(46)$ & $13 / 17(76)$ & $12 / 13(92)$ \\
\hline $1 \quad(n, \%)$ & $6 / 17(35)$ & $3 / 13(23)$ & $3 / 17(18)$ & $1 / 13(8)$ \\
\hline $2 \quad(n, \%)$ & $1 / 17(6)$ & 0 & 0 & 0 \\
\hline$(\mathrm{n}, \%)$ & 0 & $1 / 13(8)$ & 0 & 0 \\
\hline \multicolumn{5}{|l|}{ Inhalation medication } \\
\hline No $\quad(n, \%)$ & $16 / 17(94)$ & $9 / 13(69)$ & $17 / 17(100)$ & $12 / 13(92)$ \\
\hline Yes $\quad(n, \%)$ & $1 / 17(6)$ & $2 / 13(15)$ & 0 & $1 / 13(8)$ \\
\hline \multicolumn{5}{|l|}{ Admitted for RTI } \\
\hline No & $17 / 17$ & $11 / 13(85)$ & $17 / 17$ & $12 / 13(92)$ \\
\hline Yes $\quad(n, \%)$ & 0 & $2 / 13(15)$ & 0 & $1 / 13(8)$ \\
\hline \multicolumn{5}{|l|}{ Auscultatory findings } \\
\hline Normal $\quad(n, \%)$ & $16 / 17(94)$ & $9 / 13(69)$ & $16 / 17(94)$ & $12 / 13(92)$ \\
\hline Wheezing (n, \%) & 0 & $1 / 13(8)$ & $1 / 17(6)$ & $1 / 13(8)$ \\
\hline SDS height & $0.45(-0.13 / 1.03)$ & $0.44(0.09 / 0.98)$ & $0.26(-0.30 / 0.81)$ & $-0.88(-0.62 / 0.44)$ \\
\hline SDS weight & $0(-0.51 / 0.50)$ & $-0.64(-1.49 / 0.21)$ & $-0.51(-1.02 /-0.01)$ & $-0.49(-1.19 / 0.20)$ \\
\hline $\mathrm{FRC}_{\mathrm{p}}, \mathrm{mL} / \mathrm{kg}$ & $25.5(23.2 / 27.7)$ & $25.6(22.4 / 28.7)$ & $26.9(24.5 / 29.3)$ & $26.6(23.7 / 29.5)$ \\
\hline $\operatorname{Vmax}_{\mathrm{FRC}}, \mathrm{SDS}$ & $-1.42(-1.68 /-1.16)$ & $-1.41(-2.48 /-0.33)$ & $-1.63(-2.20 /-1.06)$ & $-1.46(-2.34 /-0.58)$ \\
\hline $\mathrm{RR}$, breaths/min & $33(31 / 37)$ & $39(32 / 45)$ & $30(28 / 33)$ & $30(27 / 33)$ \\
\hline
\end{tabular}

Table 2: Respiratory symptoms: $n=$ number of respiratory tract infections (RTI) in the past 6 months requiring treatment with antibiotics $(A B)$. SDS weight height are expressed as mean (SD). Lung function: $F R C_{p}$ : functional residual capacity.

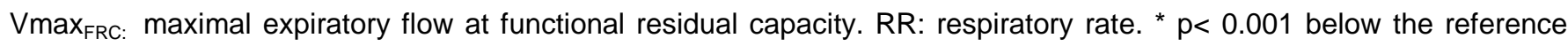
value $(\mathrm{SDS}=0)$. Mean $(95 \% \mathrm{Cl})$ values from analysis of variance are shown. 


\section{Figure legends}

\section{Flowchart (online)}

\section{Figure 1: $F R C_{p}$ in observation and surgical group.}

$\mathrm{FRC}_{\mathrm{p}}(\mathrm{mL} / \mathrm{kg})$ at 6 and 12 months (observation group; Figure 1a, surgical group 2; Figure 1b). The range of normal values (beween 13 and $26 \mathrm{~mL} / \mathrm{kg}$ ) is indicated by dotted horizontal lines.

Open circles represent CCAM: congenital cystic adenomatoid malformation, open squares represent BPS: bronchopulmonary sequestration, closed triangles represent CLE: congenital lobar emphysema, open diamonds represent BC: bronchogenic cyst.

Figure 2: V'max ${ }_{\mathrm{FRC}}$ in observation and surgical group.

Standard deviation score (SDS) $\operatorname{Vmax}_{\mathrm{FRC}}$ at 6 and 12 months (observation group; Figure 2a, surgical group: Figure 2b).

Open circles represent CCAM: congenital cystic adenomatoid malformation, open squares represent BPS: bronchopulmonary sequestration, closed triangles represent CLE: congenital lobar emphysema, open diamonds represent BC: bronchogenic cyst. 
Online Figure

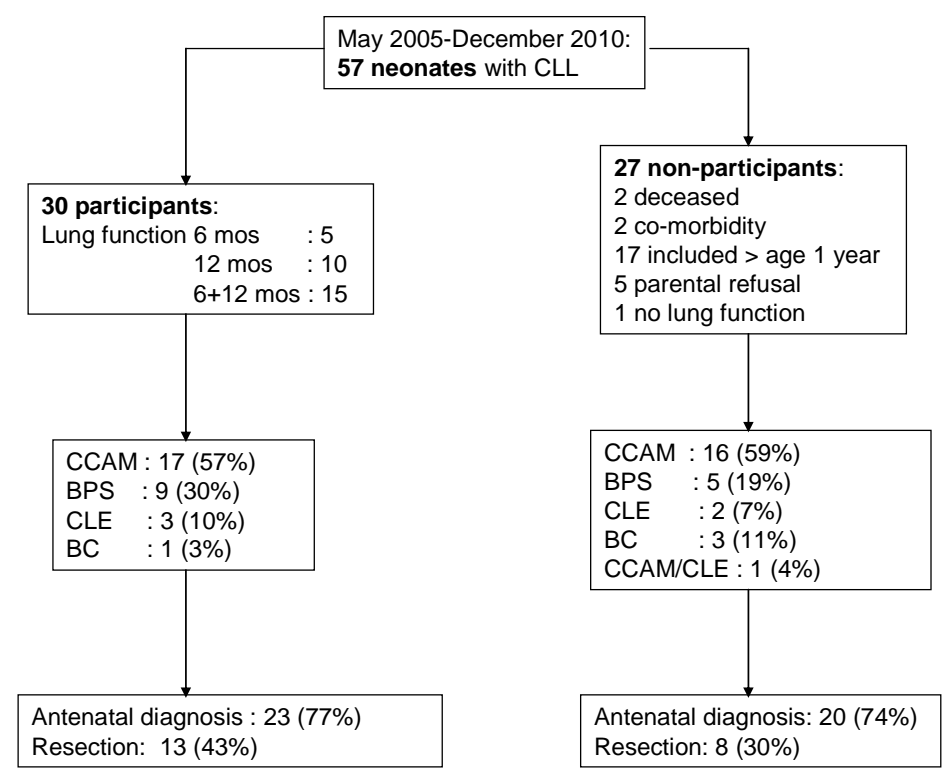

Figure 1a

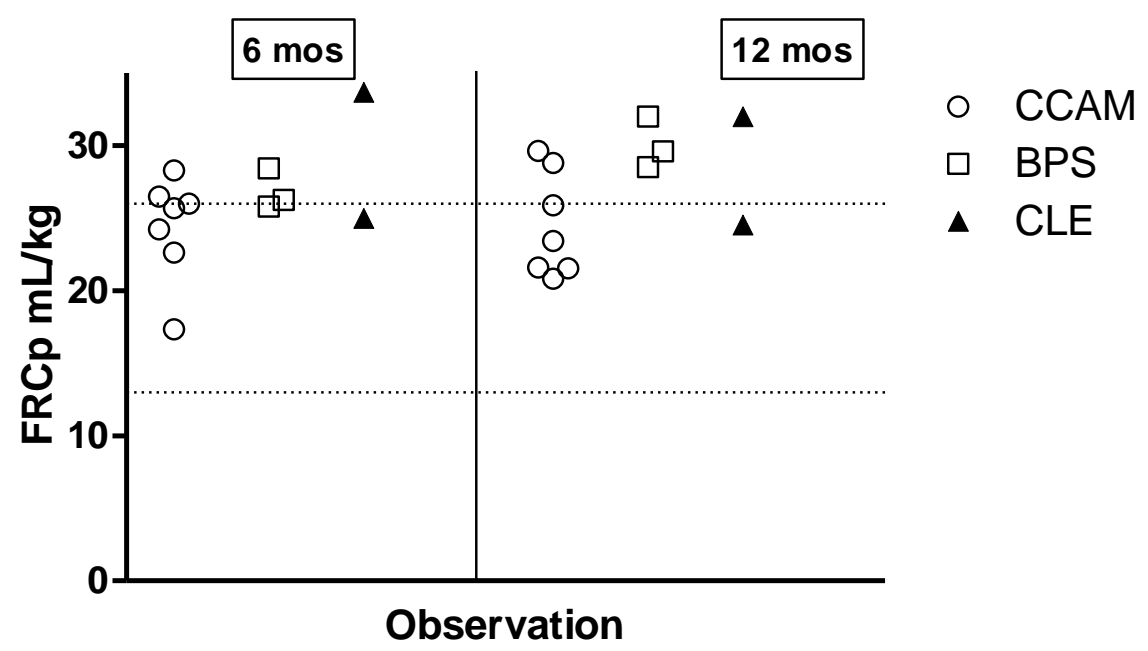


Figure $1 b$

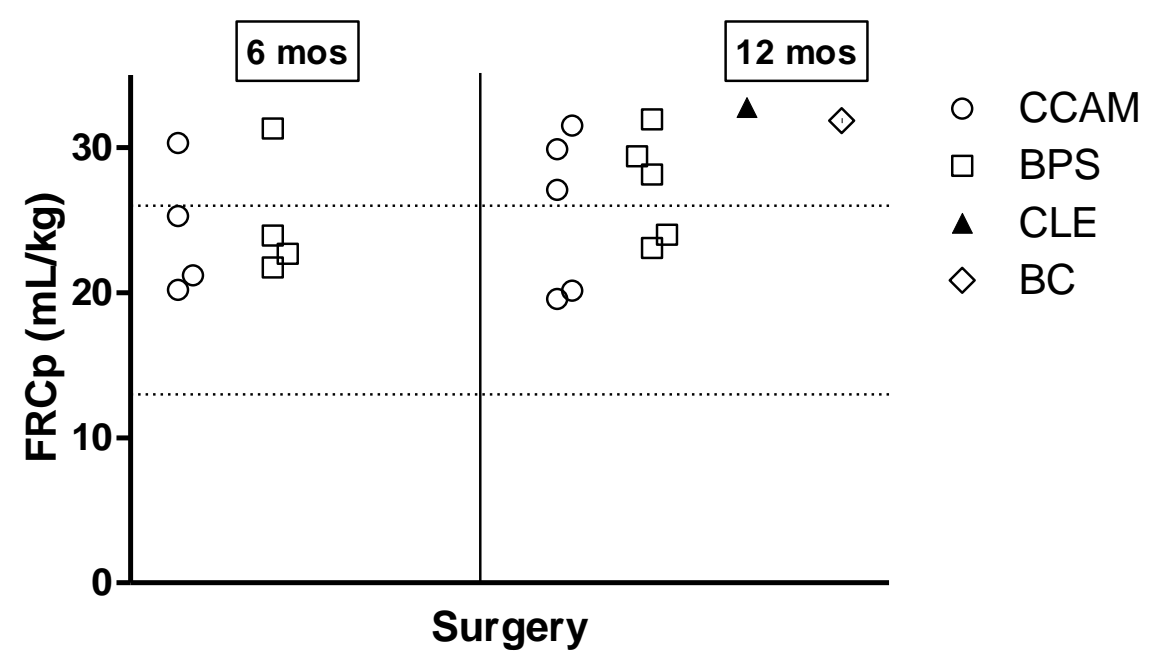

Figure 2a

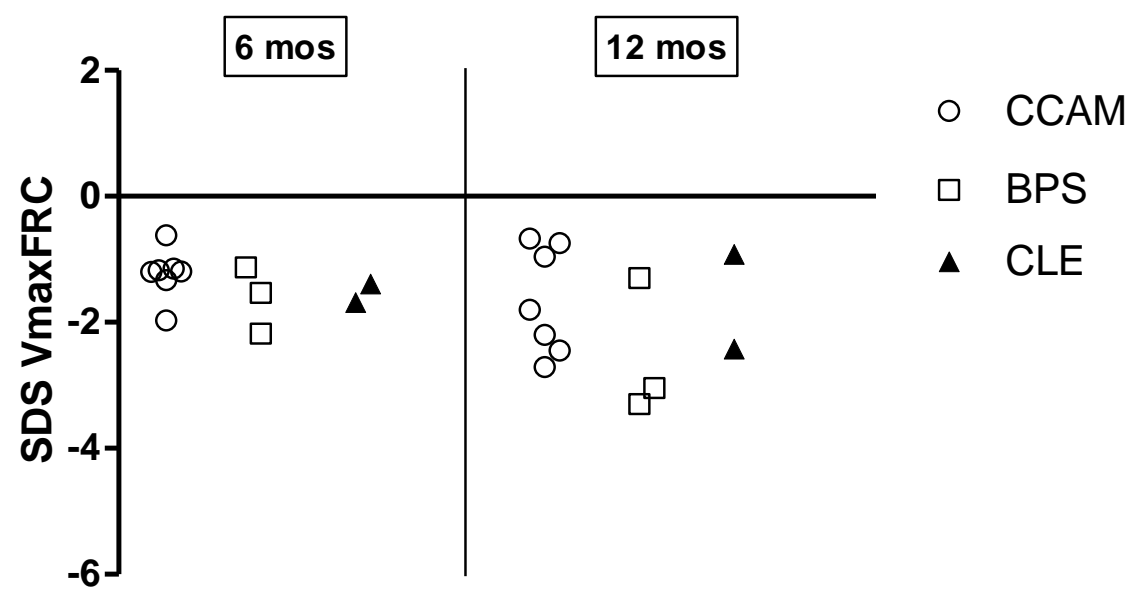

Observation 
Figure $2 b$

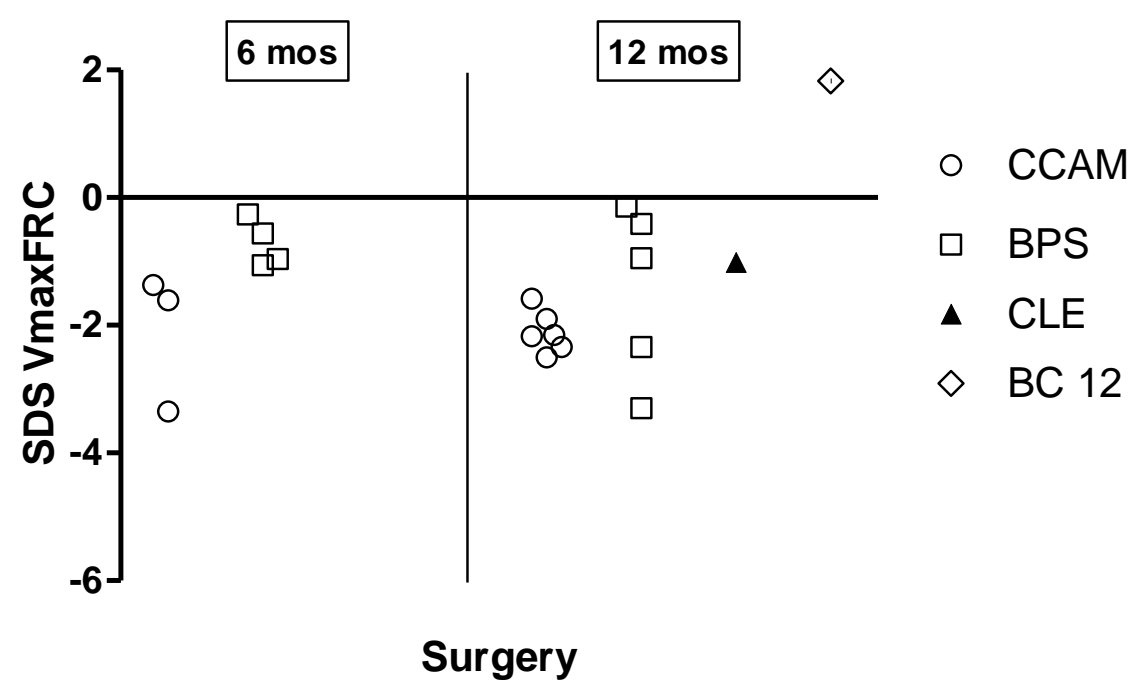




\section{Online supplement}

\section{Methods}

Of all CLL patients born in our centre between May 2005 and September 2010 we recorded data on antenatal ultrasound, gestational age, birth weight, gender, type of lung anomaly, duration of post-operative ventilation and supplemental oxygen. In the group of infants that underwent resection of the affected lung part(s), the surgical group, surgical procedure (lobectomy, pneumonectomy or non-anatomical resection) was recorded. Indications for surgery in our institution are respiratory distress with persistent need for oxygen and/or mechanical ventilation due to the presence of the congenital lung lesion. Another criterion for surgery is recurrent infection in the affected lung part(s). Asymptomatic infants, the observation group, were observed only.

The study was part of a routine follow-up program for CLL patients in which lung function, growth and developmental parameters are regularly assessed until 18 years of age [1-2]. At 6 and 12 months of age they visited our outpatient clinic and lung function and growth amongst other parameters were assessed. The Medical Ethical Review Board Erasmus MC stated that "the Medical Research in Human Subjects Act does not apply to this research proposal, since subjects are not being submitted to any handling, nor are there rules of human behaviour being imposed". Therefore approval was waived. All parents were informed and provided permission to use the data for research purposes. Lung function data were evaluated at the end of 2011.

\section{Respiratory morbidity and physical growth}

The infants were physically examined at the ages of 6 and 12 months. Examination included anthropometry and pulmonary auscultation. Respiratory rate (RR) was measured during lung function assessment. The occurrence of doctor-diagnosed respiratory tract infections requiring treatment with antibiotics and/or hospital admission in the previous 6 months, and the use of inhalation medication were assessed by questionnaires and from the medical records of our hospital at both time points. Dutch population data served as reference values for physical growth [3].

\section{Infant lung function tests}

Infant lung function tests were done at the ages of 6 and 12 months (corrected for prematurity), when children were clinically stable. Infants were sedated with chloral hydrate $(50-75 \mathrm{mg} / \mathrm{kg})$. Functional residual capacity $\left(\mathrm{FRC}_{\mathrm{p}}\right)$ was measured by whole body plethysmography (Masterscreen Babybody, Viasys, Hochberg, Germany) as described previously [4]. The earlier reference equations to compute $\mathrm{FRC}_{\mathrm{p}}$ into $\mathrm{SD}$-scores are perhaps not entirely appropriate for data obtained with the newer equipment. The use of $F R C p$ in $\mathrm{mL} / \mathrm{kg}$ is acceptable in the neonatal period, as the regression of $\mathrm{FRC}_{\mathrm{p}}$ on weight is relatively linear and passes close to the origin. Until new reference data are available, we need to interpret results cautiously. The normal range of FRCp, suggested by Hülskamp et al, is $13-26 \mathrm{ml} / \mathrm{kg}$, mean 19.6, SD 3.4 [5]. Forced expiratory flow at $\mathrm{FRC}_{\mathrm{p}}\left(\mathrm{V}^{\prime} \max _{\mathrm{FRC}}\right)$, a measure of airway patency and compressibility, was determined by the end-tidal rapid thoracoabdominal compression technique (Masterscreen Babybody, Viasys, Hochberg, Germany). Regarding V'maxFRC, we used the references values provided by Hoo and colleagues, which are based on a large representative population of healthy infants and have been used by others using similar equipment as we did [6].

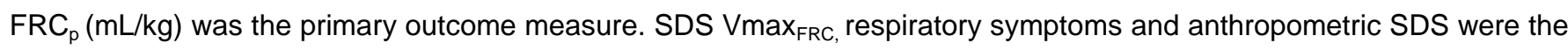
secondary outcome measures. All equipment and procedures complied with the guidelines of the ERS/ATS [7]. Adherence to these guidelines ensures an acceptable degree of precision and reproducibility. 


\section{Data Analysis}

Group comparisons were made with Mann Whitney $U$ tests. In a minority of patients, lung function was measured only at one of the two time points. Since repeated measurements ANOVA allows for missing data at one time point, mean $(95 \%$ Cl) $\mathrm{FRC}_{\mathrm{p}}, \mathrm{SDS} \mathrm{V}^{\prime} \max _{\mathrm{FRC}}$ and SDS for weight and height were evaluated longitudinally using this method [8]. The following parameters were entered as covariates in univariate Mixed Models to investigate their influence on lung function parameters: gestational age at birth, birth weight, duration of ventilation, duration of supplemental oxygen, and management - either observation or surgery. The durations of ventilation and supplemental oxygen were transformed logarithmically to reduce the effect of outlying values.

All results are expressed as number (percentage), mean (SD, 95\% Cl) or median (range) where appropriate.

The significance level was set at $p<0.05$. SPSS 17.0 (Chicago, Illinois) was used for the analyses.

\section{References}

1 Gischler SJ, van der Cammen-van Zijp MH, Mazer P, Madern GC, Bax NM, de Jongste JC, van Dijk M, Tibboel D, ljsselstijn $\mathrm{H}$ : A prospective comparative evaluation of persistent respiratory morbidity in esophageal atresia and congenital diaphragmatic hernia survivors. J Pediatr Surg 2009;44:1683-1690.

2 Gischler SJ, Mazer P, Duivenvoorden HJ, van Dijk M, Bax NM, Hazebroek FW, Tibboel D: Interdisciplinary structural follow-up of surgical newborns: A prospective evaluation. J Pediatr Surg 2009;44:1382-1389.

3 Fredriks AM, van Buuren S, Burgmeijer RJ, Meulmeester JF, Beuker RJ, Brugman E, Roede MJ, VerlooveVanhorick SP, Wit JM: Continuing positive secular growth change in the netherlands 1955-1997. Pediatr Res 2000;47:316-323.

4 Spoel M, van den Hout L, Gischler SJ, Hop WC, Reiss I, Tibboel D, de Jongste JC, ljsselstijn H: Prospective longitudinal evaluation of lung function during the first year of life after repair of congenital diaphragmatic hernia. Pediatr Crit Care Med 2011

5 Hulskamp G, Hoo AF, Ljungberg H, Lum S, Pillow JJ, Stocks J: Progressive decline in plethysmographic lung volumes in infants: Physiology or technology? Am J Respir Crit Care Med 2003;168:1003-1009.

6 Hoo AF, Dezateux C, Hanrahan JP, Cole TJ, Tepper RS, Stocks J: Sex-specific prediction equations for vmax(frc) in infancy: A multicenter collaborative study. Am J Respir Crit Care Med 2002;165:1084-1092.

7 Stocks J, Godfrey S, Beardsmore C, Bar-Yishay E, Castile R, Society EATFoSfIRFTERSAT: Plethysmographic measurements of lung volume and airway resistance. Ers/ats task force on standards for infant respiratory function testing. European respiratory society/ american thoracic society. Eur Respir J 2001;17:302-312.

$8 \quad$ Fitzmaurice GM: Applied longitudinal analysis 1st ed John Wiley \& Sons 2004 